\title{
TENSILE PROPERTIES OF POLYPROPYLENE/LINEAR LOW-DENSITY POLYETHYLENE/NANO-TITANIUM DIOXIDE NANOCOMPOSITES USING A TWO-LEVEL FACTORIAL EXPERIMENT
}

\author{
Sajjad DANESHPAYEH, Faramarz ASHENAI GHASEMI, Ismail GHASEMI
}

\begin{abstract}
In this paper, a $2^{3}$ factorial design analysis was used to study the parameters affecting the mechanical characteristics of polypropylene/linear low-density polyethylene/nano-titanium dioxide (PP/LLDPE/TiO 2 ) nanocomposites, and to optimize these factors in order to predict the maximum ultimate tensile strength (UTS), elastic modulus (EM), and yield strength (YS) simultaneously. To do this, two levels of nano-titanium dioxide $\left(\mathrm{TiO}_{2}\right.$ ), linear low-density polyethylene (LLDPE) and styreneethylene-butylene-styrene (SEBS) as the coupling agent were selected and eight experiments were conducted for every response. The most effective factors influencing the UTS, EM, and YS were found, and acceptable prediction regression models were taken. One noted that nanoparticles increased the elastic modulus. The attendance of high levels of LLDPE and SEBS resulted in a decrease in YS and UTS. Moreover, the optimum values of variables were determined by using the contour plot.
\end{abstract}

Keywords: elastic modulus; factorial design; nanocomposite; polypropylene; tensile strength

\section{INTRODUCTION}

Nowadays, polymeric products, especially polyethylene (PE) and polypropylene (PP), are developed for their low expense, good mechanical features, small weight, and other desirable characteristics [1]. Different kinds of polyethylene, containing high-density polyethylene (HDPE), low-density polyethylene (LDPE), and linear low-density polyethylene (LLDPE) are used to improve the mechanical and physical characteristics of PP [2]. Additionally, LLDPE has numerous applications, and the importance of LLDPE has increased due to its special characteristics [3].

To refine the particular characteristics of these polymers, several additives are mixed with them. Adding some microor nanoscale fillers may improve the disadvantages of neat polymers. Nanocomposites are polymers that are embedded with nanoscale fillers [4]. Polymer nanocomposites can modify the mechanical strength, heat resistance, elastic modulus, thermal degradation and viscoelasticity more than other traditional polymer composites [5]. By adding small values of nanoparticles, melt processing, polymer crystallization, and electric and thermal conductivity can be improved [6, 7].

Polymer nanocomposites have recently gained the attention of many material researchers. They usually study the effects of embedding various nanoparticles on the characteristics of polymer materials. Organic and inorganic nanoparticles can be utilized as reinforcement. Some of the most used inorganic nanoparticles are $\mathrm{SiO}_{2}, \mathrm{TiO}_{2}, \mathrm{Al}_{2} \mathrm{O}_{3}$, and $\mathrm{ZrO}_{2}$ [3]. $\mathrm{TiO}_{2}$ is a very special material due to special characteristics such as light density and thermal degradation [8]. The main problem in manufacturing the $\mathrm{TiO}_{2}$ nanocomposite is its conflict with the polymer matrix, because $\mathrm{TiO}_{2}$ is hydrophilic and the polymer matrix is hydrophobic. $\mathrm{TiO}_{2}$ nanoparticles also have a large surface area ratio which makes them aggregate easily. To avoid this, styrene ethylene-butylene-styrene (SEBS) can be applied as a coupling agent to improve the $\mathrm{TiO}_{2}$ surface [9-11] .

Many scientists have investigated the mechanical properties of polymers and polymer composites. Garcia et al. [12], for instance, added $\mathrm{SiO}_{2}$ nanoparticles to the PP matrix and observed that the impact strength and elastic modulus were improved. Selvin et al. [13] found that $\mathrm{TiO}_{2}$ nanoparticles significantly increased the elastic modulus of the polystyrene matrix. Moreover, Sirirat et al. [14] added small values of $\mathrm{TiO}_{2}$ to the PP matrix and reported an improvement in some mechanical properties of the based material. Moreover, Altan [15] showed that, by embedding $\mathrm{TiO}_{2}$ nanoparticles in the PP matrix, the elastic modulus of the structure increased, but its impact strength was reduced.

Ternary nanocomposites, including a system of the polymer matrix, elastomer, and filler, have newly been incorporated in different applications [16, 17]. Liu et al. [18] showed that, by adding $\mathrm{TiO}_{2}$ nanoparticles to PP/LLDPE, some mechanical properties of the compounds were enhanced. Furthermore, Abu Ghalia et al. [17] reported that, by embedding calcium carbonate $\left(\mathrm{CaCO}_{3}\right)$ in PP/LLDPE compounds, some of their mechanical characteristics were improved. Altan and Yildirim [19] showed that structures including $\mathrm{TiO}_{2}$ and SEBS present better mechanical characteristics compared to ones without SEBS.

Guo and $\mathrm{Li}$ [20] found that SEBS/titania nanocomposites showed good mechanical attributes. They also reported that the uniform dispersion of titania nanoparticles in the SEBS matrix increased the thermal stability of samples. Additionally, Nguyen et al. [9] concluded that some mechanical characteristics of LDPE/modified $\mathrm{TiO}_{2}$ nanocomposites increased compared to the based LDPE/unmodified structures. Xue et al. [21] verified that the coexistence of organo-montmorillonite (OMMT) and nano$\mathrm{Cu}$ in $\mathrm{Cu} / \mathrm{OMMT/LLDPE}$ nanocomposites may improve the anticorrosion properties of samples. 
Here, a $2^{3}$ factorial design was used to supply a relation for the YS, UTS, and EM of PP/LLDPE/TiO nanocomposites as a mathematical function of parameters (SEBS, $\mathrm{TiO}_{2}$, and LLDPE). Moreover, the effect of every agent on mechanical characteristics was studied and the optimal range of each parameter was found in order to achieve the best tensile properties.

\section{THE EXPERIMENTS}

\subsection{Materials}

Polypropylene (PP-Z30S, MFR-25, $230{ }^{\circ} \mathrm{C}, 2.16 \mathrm{~kg}$ ) and linear low-density polyethylene (LLDPE-0209, MFR-0.9, $190{ }^{\circ} \mathrm{C}, 2.16 \mathrm{~kg}$, and density of $0.920 \mathrm{gr} \mathrm{ml}^{-1}$ ) were procured from the Arak Petrochemical Company, Iran. The nano- $\mathrm{TiO}_{2}$ rutile structure with the mean size of $30 \mathrm{~nm}$ and density of $4.23 \mathrm{~g} / \mathrm{cm}$ was obtained from the Iranian Nanomaterials Pioneers (INP), Iran. Moreover, the KRATON polymer type G, namely styrene-ethylene/butylene-styrene (SEBS), was used as a coupling agent. The compound was prepared by using a co-rotating screw extruder (ZSK 25 P8.2E WLE) with a 170 to $190{ }^{\circ} \mathrm{C}$ temperature range. Next, they were made as granules. Granules were injected with the help of an injection molding machine (IMAN MACHINE $125 \mathrm{~g}$ ) with the temperature profiles of $190-200-210^{\circ} \mathrm{C}$, and the samples were hence prepared.

\subsection{Mechanical Testing}

The elastic modulus, yield, and ultimate tensile strength were specified by a Zwick/Roell-Z100 machine (Germany) due to the ASTM D638 standard with the strain rate of 50 $\mathrm{mm} / \mathrm{min}$ at room temperature. Fig. 1 shows a sample before and after the tensile tests.

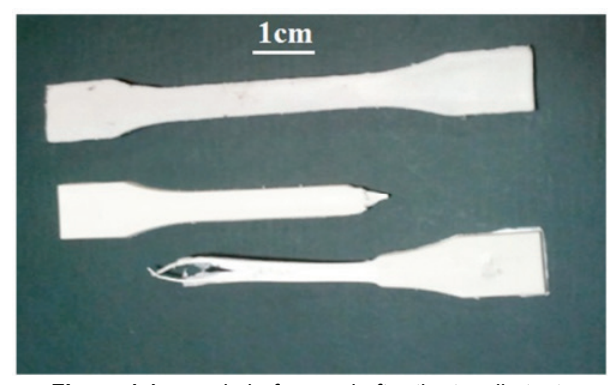

Figure $1 \mathrm{~A}$ sample before and after the tensile tests

\subsection{Experiment Design}

The factorial design of experiments (DOE) is a good and well-known procedure of testing in which all parameters are changed together in the experimental runs [22]. In this work, DOE was applied to study the effect of significant factors on the EM, YS, and UTS of PP/LLDPE/TiO 2 nanocomposites. The main aspect in DOE is the choice of control factors [23]. Here, the studied factors were LLDPE, $\mathrm{TiO}_{2}$ nanoparticles, and SEBS. After the choice of factors, the $2^{3}$ factorial design method was offered the levels which were coded within the
-1 and +1 range in such a way that the researcher could choose an experimental design from a list of designs.

The $2^{k}$ factorial design is one of the most widely applied designs to investigate the effects of various parameters on a particular response, where $k$ is the number of parameters and the base 2 shows the level of treatment for each discussed parameter [22]. The performed design is shown in Tab. 1 which briefly discusses the parameters and the change of their levels. Furthermore, different modes of combining materials via the software were determined. As presented in Tab. 2, eight tests had to be prepared for each response having three replicates.

Table 1 Level of factors applied to study the effect of LLDPE, $\mathrm{TiO}_{2}$ and SEBS

\begin{tabular}{|c|c|c|c|c|}
\hline \multicolumn{2}{|c|}{ Factors } & LLDPE & $\mathrm{TiO}_{2}$ & SEBS \\
\hline \multirow{2}{*}{ Level } & -1 (low) & 40 & 0 & 0 \\
\cline { 2 - 5 } & +1 (high) & 60 & 2 & 3 \\
\hline
\end{tabular}

Table 2 Results of running the software

\begin{tabular}{|l|c|c|c|c|c|c|c|c|}
\hline \multicolumn{7}{|c|}{ Full Factorial Design } \\
\hline \multicolumn{1}{|c|}{ Sample No. } & 1 & 2 & 3 & 4 & 5 & 6 & 7 & 8 \\
\hline PP (Wt. \%) & 80 & 60 & 78 & 58 & 77 & 57 & 75 & 55 \\
\hline LLDPE (Wt. \%) & 20 & 40 & 20 & 40 & 20 & 40 & 20 & 40 \\
\hline $\mathrm{TiO}_{2}$ (Wt. \%) & 0 & 0 & 2 & 2 & 0 & 0 & 2 & 2 \\
\hline SEBS (Wt. \%) & 0 & 0 & 0 & 0 & 3 & 3 & 3 & 3 \\
\hline Random order of samples & 3 & 2 & 8 & 1 & 6 & 4 & 7 & 5 \\
\hline
\end{tabular}

As three parameters at two levels were assumed, the experimental design was named a $2^{3}$ full factorial design that needed eight test runs for every response. The average of results is presented in Tab. 3 .

Table 3 The experimental results for YS, UTS and EM

\begin{tabular}{|l|c|c|c|c|c|c|c|c|}
\hline Sample No. & 1 & 2 & 3 & 4 & 5 & 6 & 7 & 8 \\
\hline YS (MPa) & 19.63 & 12.9 & 15.33 & 11.56 & 21.86 & 13.33 & 16.16 & 11.9 \\
\hline UTS (MPa) & 23.63 & 19.5 & 21.86 & 18.3 & 23.93 & 18.03 & 20.33 & 19 \\
\hline EM (MPa) & 223 & 189 & 226.6 & 207.3 & 212 & 184.6 & 222.6 & 199.3 \\
\hline
\end{tabular}

\section{RESULTS AND DISCUSSION}

\subsection{Analysis of Variance (ANOVA) for Tensile Strength}

The $p$-value is described as the minimum level of importance leading to the rejection of the null hypothesis and interaction is a kind of action that occur as two or more objects have an effect upon one another [22]. $F$ value is the measure of variation in the data about the mean. Due to the $p$-value described as the minimum level of importance leading to the rejection of the null hypothesis, it seems that the effect of every parameter was statistically important at the $p$-value of less than 0.05 .

The ANOVA results for YS are presented in Tab. 4. One sees that LLDPE $(P=0.000), \mathrm{TiO}_{2}(P=0.000)$, SEBS $(P=$ $0.001), \mathrm{LLDPE} \times \mathrm{TiO}_{2}(P=0.000)$, and LLDPE $\times \operatorname{SEBS}(P=$ 0.021 ) with the p-values below or equal to 0.05 for a $95 \%$ assurance level should be statistically important for YS. In addition to that, Fisher's variance ratio ( $F$-value) is the amount of variability from the mean. Applying the $F$-value, the respective significance of each parameter and its interaction would be:

LLDPE $>\mathrm{TiO}_{2}>$ LLDPE $\times \mathrm{TiO}_{2}>$ SEBS $>$ LLDPE $\times$ SEBS. 
Table 4 ANOVA results for YS

\begin{tabular}{|l|c|c|}
\hline \multicolumn{1}{|c|}{ Source } & $F$ & $P$ \\
\hline Main Effects & 249.31 & 0.000 \\
\hline LLDPE & 555.84 & 0.000 \\
\hline $\mathrm{TiO}_{2}$ & 175.14 & 0.000 \\
\hline $\mathrm{SEBS}$ & 16.95 & 0.001 \\
\hline 2-Way Interactions & 21.94 & 0.000 \\
\hline LLDPE $\times \mathrm{TiO}_{2}$ & 57.56 & 0.000 \\
\hline LLDPE $\times \mathrm{SEBS}$ & 6.51 & 0.021 \\
\hline $\mathrm{TiO}_{2} \times \mathrm{SEBS}$ & 1.76 & 0.203 \\
\hline
\end{tabular}

The effects of the LLDPE $\times \mathrm{TiO}_{2}$ interaction on YS are greater than the importance effect of a single-factor (i.e. factor SEBS). The important interaction of LLDPE and $\mathrm{TiO}_{2}$ shows that these parameters are related, i.e. if the level of one parameter varies, the effect of the other one varies, too.

The ANOVA results of UTS are presented in Tab. 5. It is clear that LLDPE $(P=0.000), \mathrm{TiO}_{2}(P=0.000)$, SEBS $(P$ $=0.003)$, and $\operatorname{LLDPE} \times \mathrm{TiO}_{2}(P=0.000)$ whose $\mathrm{p}$-values were below or equal to 0.05 for UTS should be statistically important. Moreover, from the $F$-values in Tab. 5, the relative importance of each factor and its interactions would be:

LLDPE $>\mathrm{TiO}_{2}>$ LLDPE $\times \mathrm{TiO}_{2}>\mathrm{SEBS}$.

Table 5 ANOVA results for UTS

\begin{tabular}{|l|c|c|}
\hline \multicolumn{1}{|c|}{ Source } & $F$ & $P$ \\
\hline Main Effects & 261.86 & 0.000 \\
\hline LLDPE & 678.05 & 0.000 \\
\hline $\mathrm{TiO}_{2}$ & 95.35 & 0.000 \\
\hline $\mathrm{SEBS}$ & 12.16 & 0.003 \\
\hline 2-Way Interactions & 27.04 & 0.000 \\
\hline LLDPE $\times \mathrm{TiO}_{2}$ & 80.12 & 0.000 \\
\hline $\mathrm{LLDPE}_{\mathrm{SSEBS}}$ & 0.66 & 0.428 \\
\hline $\mathrm{TiO}_{2} \times \mathrm{SEBS}$ & 0.34 & 0.569 \\
\hline
\end{tabular}

Table 6 ANOVA results for EM

\begin{tabular}{|c|c|c|}
\hline Source & $F$ & $P$ \\
\hline Main Effects & 235.29 & 0.000 \\
\hline LLDPE & 553.29 & 0.000 \\
\hline $\mathrm{TiO}_{2}$ & 114.57 & 0.000 \\
\hline SEBS & 38.20 & 0.000 \\
\hline 2-Way Interactions & 6.25 & 0.005 \\
\hline LLDPE $\times \mathrm{TiO}_{2}$ & 17.82 & 0.001 \\
\hline LLDPE $\times$ SEBS & 0.36 & 0.555 \\
\hline $\mathrm{TiO}_{2} \times \mathrm{SEBS}$ & 0.57 & 0.462 \\
\hline
\end{tabular}

The EM ANOVA results are presented in Tab. 6. It is observed that LLDPE $(P=0.000), \mathrm{TiO}_{2}(P=0.000)$, SEBS $(P=0.000)$, and LLDPE $\times \mathrm{TiO}_{2}(P=0.001)$, whose $p$-values were below or equal to 0.05 for EM would be statistically important. Moreover, from the $F$-values in Tab. 6, the relative importance of each factor and its interactions would be:

\section{LLDPE $>\mathrm{TiO}_{2}>\mathrm{SEBS}>\mathrm{LLDPE} \times \mathrm{TiO}_{2}$.}

The multiple regression analysis was performed on the experimentally collected data for the YS, UTS, and EM of the PP/LLDPE/ $/ \mathrm{TiO}_{2}$ nanocomposites. Here, the analysis was done by the Minitab ${ }^{\circledR} 16$ software which applies the ordinary least squares technique to find the regression function.
Relying on ANOVA for YS, UTS, and EM, a fitted regression model with statistical importance was found as follows:

Yield Strength $=15313-2.888 \mathrm{LLDPE}-1.621 \mathrm{TiO}_{2}+$ $0.504 \mathrm{SEBS}+0.929 \mathrm{LLDPE} \times \mathrm{TiO}_{2}-0.312 \mathrm{LLDPE} \times \mathrm{SEBS}$

R-sq: 98.07\%, R-sq(Pred): 95.67\%, R-sq(Adj): 97.23\%

Ultimate Tensile Strength $=20.575-1.867 \mathrm{~L}$
$0.7 \mathrm{TiO}_{2}-0.25 \mathrm{SEBS}+0.642 \mathrm{LLDPE} \times \mathrm{TiO}_{2}$

R-sq: $98.28 \%$ R-sq(Pred): 96.13\%, R-sq(Adj): 97.53\%

Elastic Modulus $=208.08-13 \mathrm{LLDPE}+5.92 \mathrm{TiO}_{2}-$

3.42SEBS + 2.33LLDPE $\times \mathrm{TiO}_{2}$

R-sq: 97.86\%, R-sq(Pred): 95.18\%, R-sq(Adj): 96.92\%

From Eq. (2), one sees that all factors had a negative main effect on UTS. Thus, a lower factor setting $(-1)$ would result in a higher response. In the situation of Eq. (1), an increase in $\mathrm{LLDPE} \times \mathrm{TiO}_{2}$ and SEBS from small to high levels resulted in $2.77 \%$ and $6.76 \%$ increases in $\mathrm{YS}$, whereas an increase in LLDPE and $\mathrm{TiO}_{2}$ resulted in a decrease in YS by $31.7 \%$ and $19.14 \%$. Thus, LLDPE had a maximum effect on YS with a $31.7 \%$ contribution. In the case of Eq. (2), by adding of LLDPE, $\mathrm{TiO}_{2}$, and SEBS decreased UTS by $16.63 \%, 6.58 \%$, and $2.40 \%$, respectively. Therefore, LLDPE had a maximum effect on UTS with a $16.63 \%$ contribution. In Eq. (3), an increase in $\mathrm{TiO}_{2}$ and LLDPE $\times \mathrm{TiO}_{2}$ from low to high levels resulted in $2.57 \%$ and $5.85 \%$ increases in EM, whereas an increase in LLDPE and SEBS decreased EM by $11.76 \%$ and $3.2 \%$, respectively. Hence, LLDPE had a maximum effect on EM with a $11.76 \%$ contribution.

A verified model must predict the response with good accuracy with respect to the experimental data. Model adequacy is checked by R-Sq, R-Sq (adj), and R-Sq (pred). A R-Sq value near $100 \%$ means a reliable fit to the experimental data [22]. Based on the ANOVA results, the Rsquared of the regression equations was $98.07 \%$ for YS, $98.28 \%$ for UTS, and $97.86 \%$ for EM, which means that the model is verified. The adjusted R-square was $97.23 \%$ for YS, $97.53 \%$ for UTS, and $96.92 \%$ for EM, which accounts for the amount of predictors in the model. The prediction R-squared statistic was calculated to be $95.67 \%$ for YS, $96.13 \%$ for UTS, and $95.18 \%$ for EM. Because the predicted R-square values were near the R-square and the adjusted R-square values for every response, none of the models appeared to be overfitting and none had an adequate predictive ability [22].

\subsection{Main Effects and Interaction Plot for Yield Strength}

The main effects plot in Fig. 2 indicates that YS decreases as LLDPE and $\mathrm{TiO}_{2}$ contents increase. Therefore, the maximum YS of PP/LLDPE/ $/ \mathrm{TiO}_{2}$ nanocomposites could be found at a lower LLDPE and $\mathrm{TiO}_{2}$. Moreover, Fig. 2 shows that by increasing the amount of the SEBS factor increases the yield strength. The relative strength of the effect of different parameters can also be seen. The main effects 
plot for YS (Fig. 2) showed that LLDPE was the most important factor.

Fig. 3 shows the interaction plot between the three discussed factors, namely $\mathrm{LLDPE}, \mathrm{TiO}_{2}$, and SEBS for YS, respectively. The plots, known as interaction plots, are employed to explain important interactions between process parameters. The interaction plot summarizes the interaction between the maximum and minimum amounts of each factor. From these plots, one sees that the initial interaction happened between LLDPE and $\mathrm{TiO}_{2}$ for YS, demonstrated by non-parallel lines.

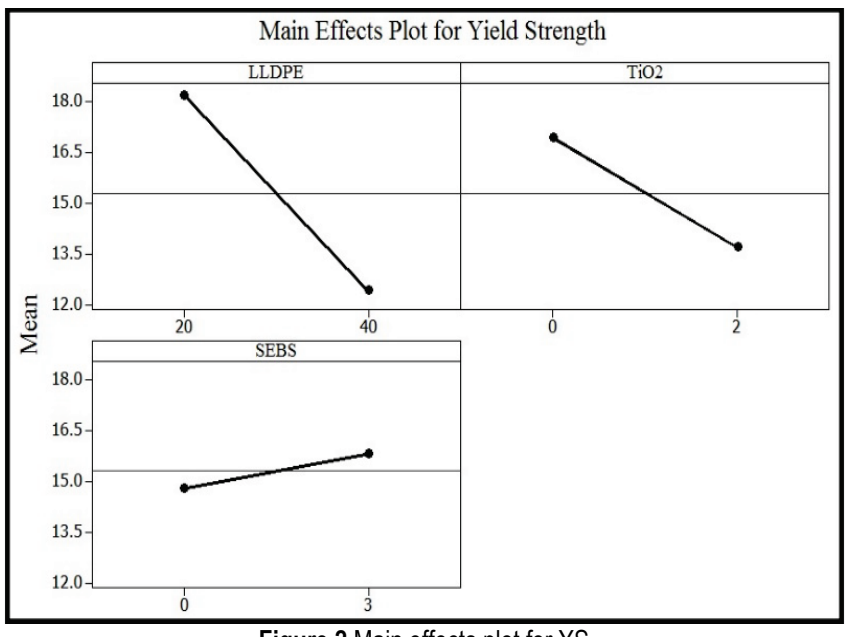

Figure 2 Main effects plot for YS

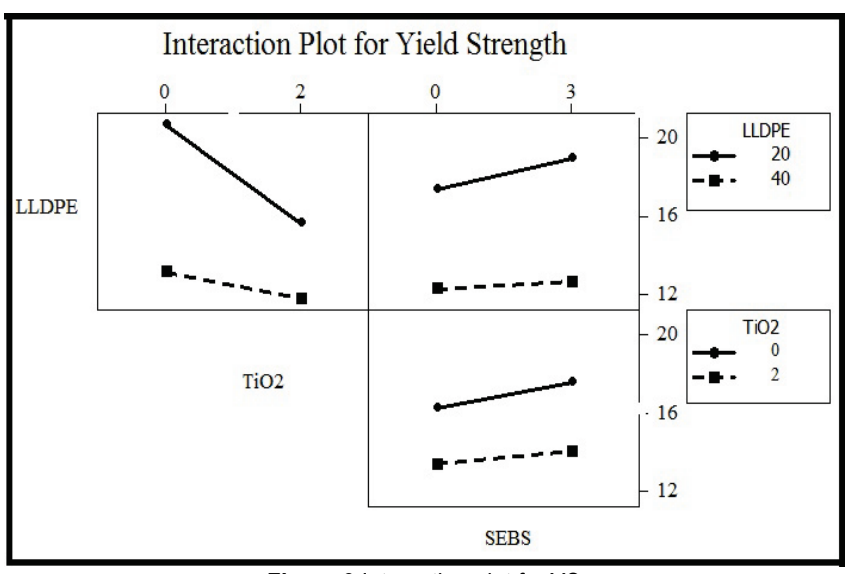

Figure 3 Interaction plot for YS

According to Fig. 3, at a low level of LLDPE (20 wt. \%) and $\mathrm{TiO}_{2}(0$ wt. \%), the interaction was very important, but adding both parameters produced a low interaction. However, the important interaction of LLDPE versus $\mathrm{TiO}_{2}$ for YS showed that a lower $\mathrm{TiO}_{2}(0 \mathrm{wt}$. \%) would result in an improvement in the YS of $\mathrm{PP} / \mathrm{LLDPE} / \mathrm{TiO}_{2}$ nanocomposites when factor LLDPE was under the low level (20 wt. \%), while the influence of $\mathrm{TiO}_{2}$ was reduced at the high level of LLDPE (40 wt. \%). These data for YS suggested that the ideal $\mathrm{TiO}_{2}$ of PP/LLDPE/TiO 2 nanocomposites differs from the LLDPE. The models with low $\mathrm{TiO}_{2}$ show a large YS when LLDPE is low, and the models with great $\mathrm{TiO}_{2}$ indicate a low YS when LLDPE is high.

\subsection{Main Effects and Interaction Plot for Ultimate Tensile Strength}

The main effects plot in Fig. 4 indicates that increasing the amount of all three major factors, especially polyethylene, the ultimate tensile strength is reduced. LLDPE decreased UTS for LLDPE, which was much smoother than PP. Therefore, the maximum UTS of $\mathrm{PP} / \mathrm{LLDPE} / \mathrm{TiO}_{2}$ nanocomposites would be reached at a less amount of LLDPE, $\mathrm{TiO}_{2}$, and SEBS. The relative strength of the effect of different parameters could also be seen. The main effects plot for UTS (Fig. 4) showed that LLDPE was the most important factor.

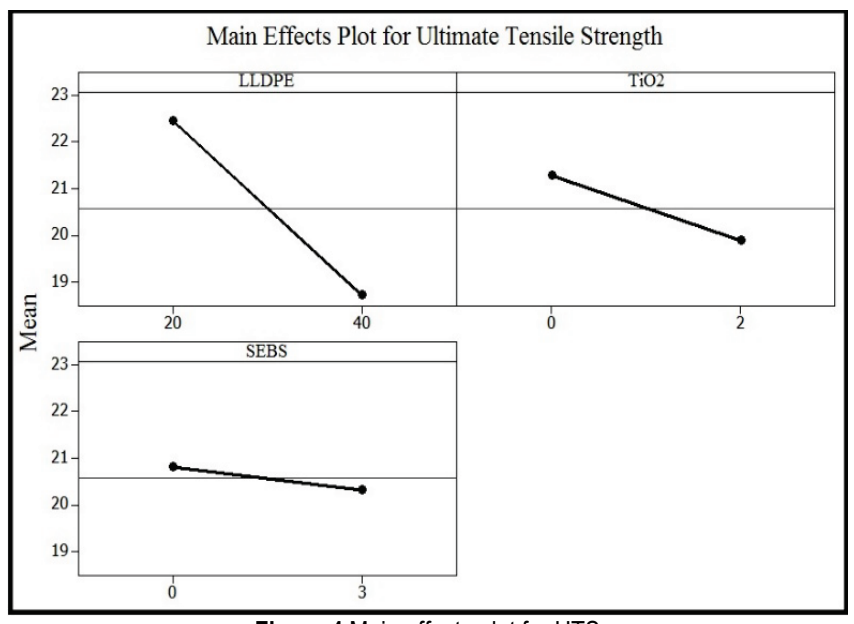

Figure 4 Main effects plot for UTS

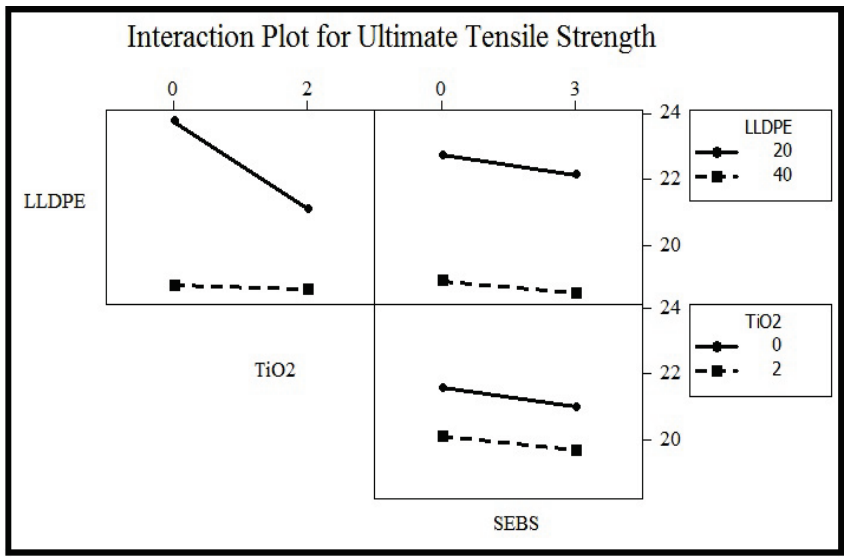

Figure 5 Interaction plot for UTS

Fig. 5 demonstrates the interaction plot between the three discussed factors, namely LLDPE, $\mathrm{TiO}_{2}$, and SEBS, for UTS, respectively. From the plot, one sees that the initial interaction happened between LLDPE and $\mathrm{TiO}_{2}$ for UTS, showed by non-parallel lines.

Fig. 5 shows that, at the low levels of LLDPE (20 wt. \%) and $\mathrm{TiO}_{2}(0$ wt. \%), the interaction was very important, but by adding both parameters, it produced a low interaction. However, the important interaction of LLDPE in respect to $\mathrm{TiO}_{2}$ for UTS showed that lower $\mathrm{TiO}_{2}(0$ wt. $\%)$ would result in an increase in the UTS of $\mathrm{PP} / \mathrm{LLDPE} / \mathrm{TiO}_{2}$ nanocomposites when LLDPE was under the low level (20 
wt. \%), while the effect of $\mathrm{TiO}_{2}$ was reduced at the high level of LLDPE (40 wt. \%). These data for UTS suggested that the ideal $\mathrm{TiO}_{2}$ of $\mathrm{PP} / \mathrm{LLDPE} / \mathrm{TiO}_{2}$ nanocomposites differs with LLDPE. The models with low $\mathrm{TiO}_{2}$ show large UTS when LLDPE is low, and the models with high $\mathrm{TiO}_{2}$ demonstrate small UTS when LLDPE is high.

\subsection{Main Effects and Interaction Plot for Elastic Modulus}

The main effects plot in Fig. 6 indicates that the elastic modulus decreased as LLDPE and SEBS varied from a low to a high level. Consequently, the maximum elastic modulus of PP/LLDPE/TiO 2 nanocomposites could be obtained at lower LLDPE and SEBS.

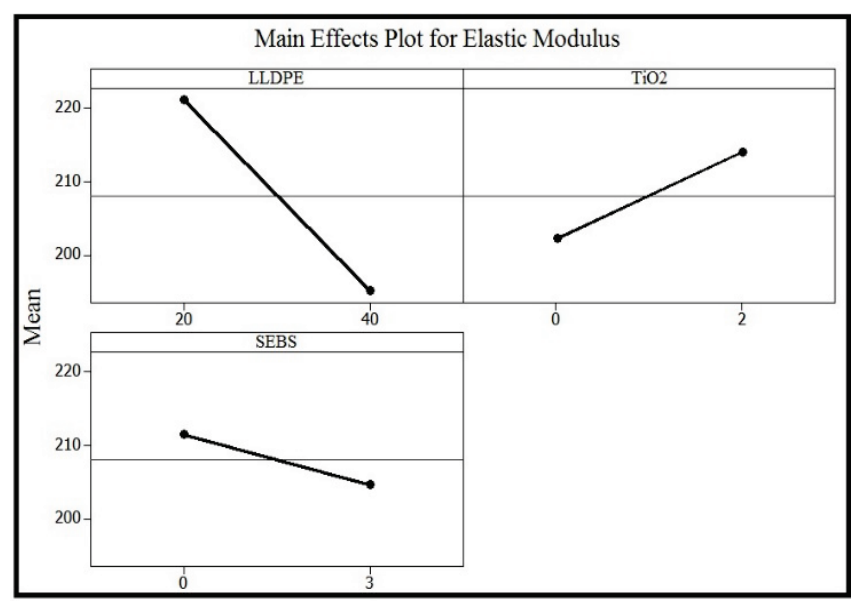

Figure 6 Main plots for EM

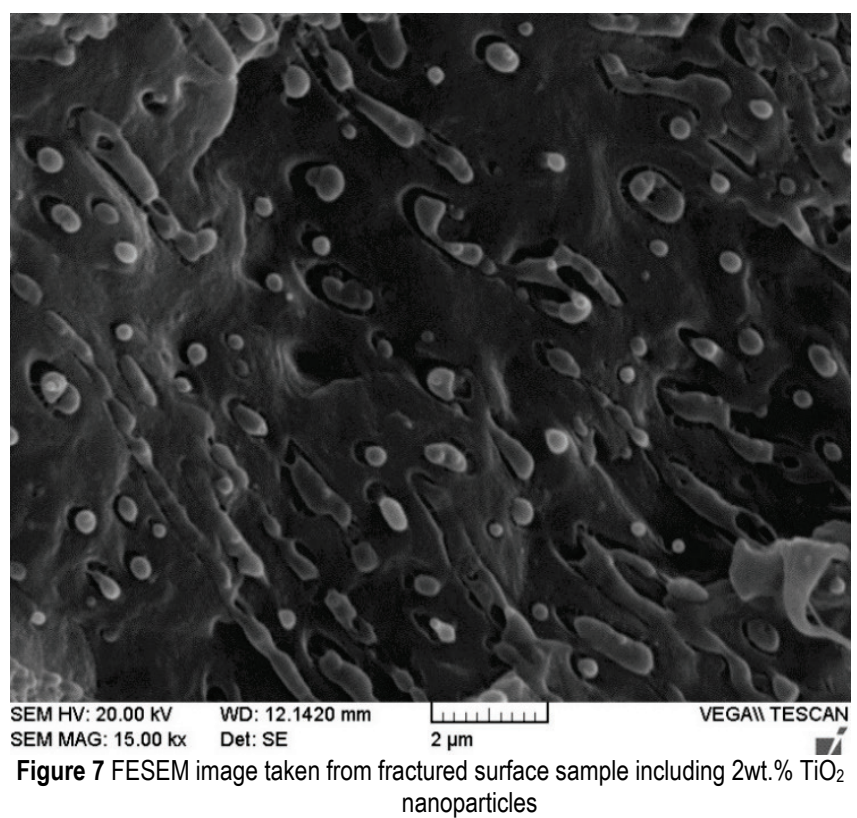

However, regarding the mechanical properties of the variables, namely EM, a variation of $\mathrm{TiO}_{2}$ seems to have a significantly increasing effect, similar to Selvin's [13] finding about polystyrene/ $/ \mathrm{TiO}_{2}$ nanocomposites. The relative strength of the effect of different parameters may also be seen. The main effects plot for EM (Fig. 6) showed that
LLDPE was the most important factor. The elastic modulus of polymer nanocomposites largely depends on the good dispersion of nanoparticles in the matrix. Fig. 7 shows field emission scanning electron microscopy (FESEM) images taken from the samples' fractured surface. It can be observed from Fig. 7 that nanoparticles are well dispersed in the matrix. As a result, titanium oxide nanoparticles lead to an increase in the elastic modulus.

Fig. 8 illustrates the interaction plot between the three investigated parameters, namely LLDPE, $\mathrm{TiO}_{2}$, and SEBS, for EM, respectively. One could see that the initial interaction happened between LLDPE and $\mathrm{TiO}_{2}$ for EM, indicated by non-parallel lines (Fig. 8). Fig. 8 shows that, at the low levels of LLDPE (20 wt. \%) and $\mathrm{TiO}_{2}(0 \mathrm{wt}$. \%), the interaction was highly significant, and that increasing both parameters produced a good interaction and increased the EM. However, the important interaction of LLDPE versus $\mathrm{TiO}_{2}$ for EM showed that a high $\mathrm{TiO}_{2}(2 \mathrm{wt}$. \%) would result in an increase in the EM of PP/LLDPE/TiO ${ }_{2}$ nanocomposites when LLDPE was under the high level $\left(40 \mathrm{wt}\right.$. \%), while the effect of $\mathrm{TiO}_{2}$ was reduced at the low level of LLDPE (20 wt. \%). These data for EM suggested that the ideal $\mathrm{TiO}_{2}$ of $\mathrm{PP} / \mathrm{LLDPE} / \mathrm{TiO}_{2}$ nanocomposites varied with LLDPE. The models with high $\mathrm{TiO}_{2}$ show large EM when LLDPE is high, and the models with low $\mathrm{TiO}_{2}$ indicate small EM when LLDPE is low.

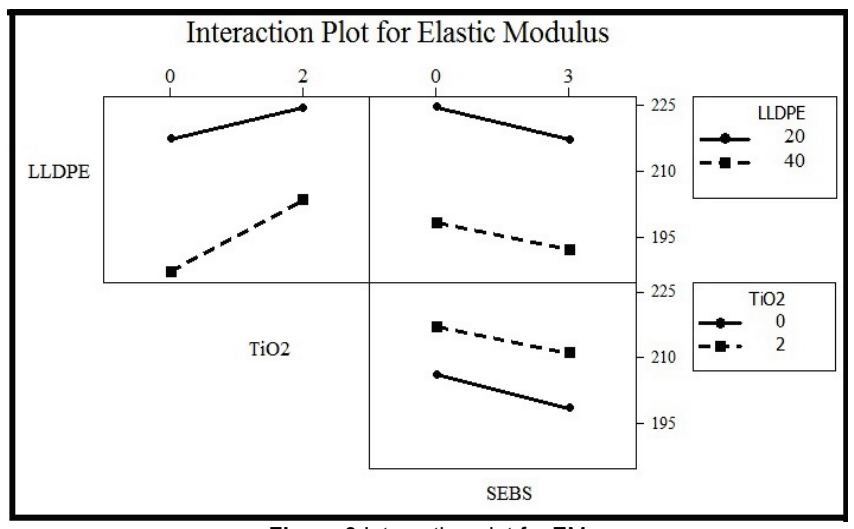

Figure 8 Interaction plot for EM

\subsection{Optimal Ranges to Achieve the Best Tensile Properties}

Mini-tab uses a contour plot to obtain the optimal areas of tensile properties. Contour or level plots are a method to present a three-dimensional surface on a two-dimensional plane. It graphs two predictor variables X Y on the y-axis and a response variable $\mathrm{Z}$ as contours. In this graphs, darker regions indicate higher responses values. They are beneficial for the creation of a favorable response. They present the contribution of two parameters simultaneously, and another parameter is retained at its middle level.

Fig. 9 presents the contour plot of the ultimate tensile strength as a function of $\mathrm{TiO}_{2} *$ LLDPE, SEBS*LLDPE, and $\mathrm{TiO}_{2} *$ SEBS. In any of these three modes, the third factor has been fixed in the middle level. Fig. 9 shows that to achieve the best ultimate tensile strength, low amounts of LLDPE (Less than 25 wt. \%) and average amounts of titanium dioxide nanoparticles and SEBS should be used. B using this 
combination, the ultimate tensile strength of more than 32 MPa can be achieved. Based on Fig. 9, the presence of high values of LLDPE (more than 35 wt.\%) led to a significant reduction in the ultimate tensile strength.

Fig. 10 depicts the contour plot of the elastic modulus as a function of $\mathrm{TiO}_{2} *$ LLDPE, SEBS*LLDPE, and $\mathrm{TiO}_{2} *$ SEBS. In any of these three modes, the third factor has been fixed in the middle level. It is clear that, to achieve the best elastic modulus, low amounts of LLDPE and SEBS and high amounts of titanium dioxide nanoparticles should be used. By using this combination, the elastic modulus of more than $220 \mathrm{MPa}$ can be achieved. Based on Fig. 9, the presence of high values of $\mathrm{TiO}_{2}$ led to a significant increase in the elastic modulus.

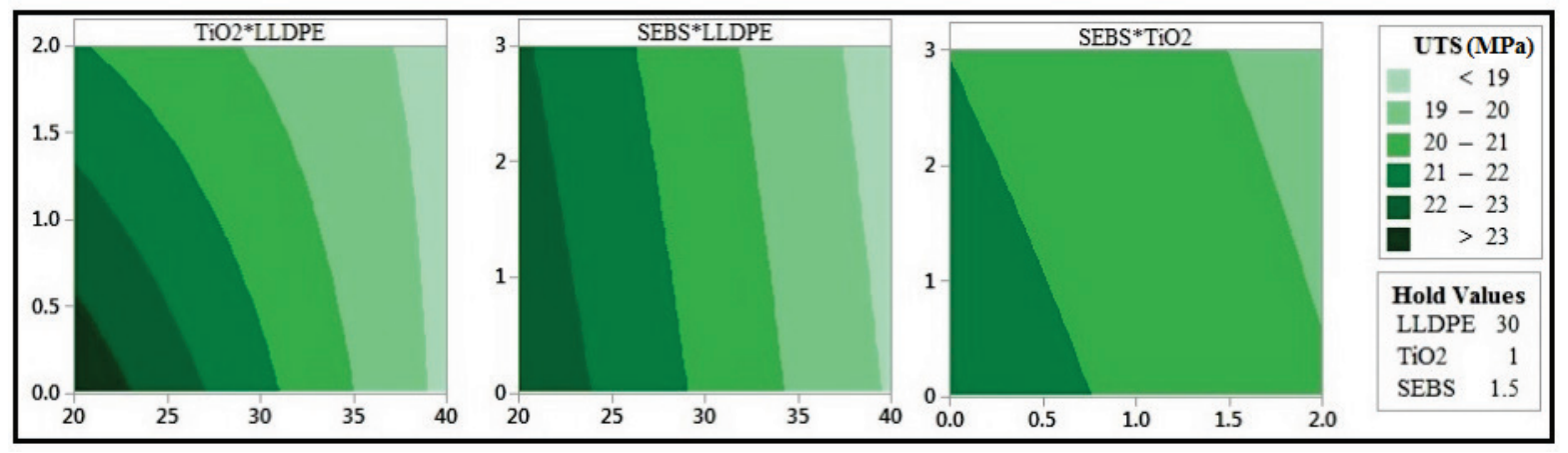

Figure 9 The contour plots of ultimate tensile strength

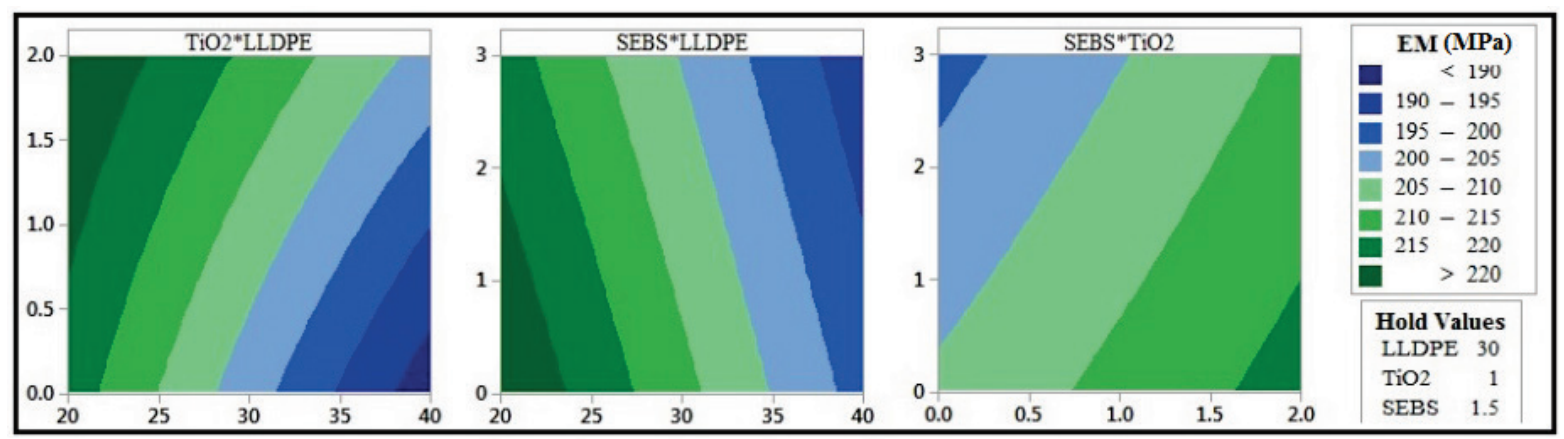

Figure 10 The contour plots of elastic modulus

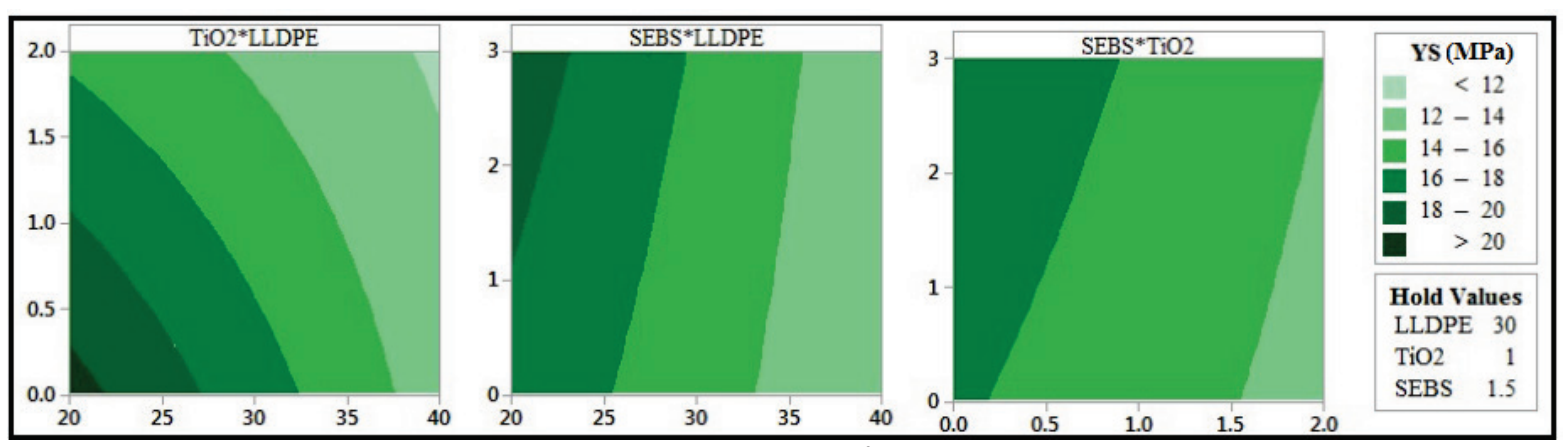

Figure 11 The contour plots of yield strength

Fig. 11 presents the contour plot of yield strength as a function of $\mathrm{TiO}_{2} *$ LLDPE, SEBS*LLDPE, and $\mathrm{TiO}_{2} *$ SEBS. In any of these three modes, the third factor has been fixed in the middle level. It is observed from Figure 11 that to achieve more than $20 \mathrm{MPa}$ for yield strength, the smallest amount of polyethylene (about 20 wt.\%) with the highest amount of nanoparticles and compatibilizer should be combined. Based on Fig. 11, the presence of high values of LLDPE (more than $25 \mathrm{wt} . \%$ ) led to a significant reduction in yield strength.

\section{CONCLUSIONS}

An optimization method, in which the factorial design, mathematical modelling and contour plots were used for the prediction of the mechanical properties of $\mathrm{PP} / \mathrm{LLDPE} / \mathrm{TiO}_{2}$ nanocomposites, has been studied. The following results were obtained:

- It was observed that the most important factors were LLDPE and $\mathrm{TiO}_{2}$, which influenced YS, UTS, and EM, while SEBS was relatively less significant.

- From the main effects and interaction plot, one sees that by adding SEBS from low to high levels, there was a 
$6.76 \%$ increase in YS, whereas an increase in LLDPE led to a decrease in YS by $31.7 \%$. An increase in LLDPE and SEBS decreased the UTS to $16.63 \%$ and $2.40 \%$, respectively. Moreover, an increase in $\mathrm{TiO}_{2}$ and LLDPE $\times \mathrm{TiO}_{2}$ (from a low to a high level) resulted in $2.57 \%$ and $5.85 \%$ increases in EM, respectively.

- The optimized ranges of variables on the tensile properties were found by using the contour plot. The results show that the most improved tensile properties were obtained in the low level of LLDPE and SEBS and the middle level of titanium dioxide nanoparticles.

\section{REFERENCES}

[1] Zapata, P. A., Rabagliati, F. M., Lieberwirth, I., Catalina, F., \& Corrales, T. (2014). Study of the photodegradation of nanocomposites containing $\mathrm{TiO}_{2}$ nanoparticles dispersed in polyethylene and in poly (ethylene-cooctadecene). Polym Degrad Stabil, 109, 106-114.

https://doi.org/10.1016/j.polymdegradstab.2014.06.020

[2] Chen, J. H., Zhong, J. C., Cai, Y. H., Su, W. B., \& Yang, Y. B. (2007). Morphology and thermal properties in the binaryblends of poly (propylene-co-ethylene) copolymer andisotactic polypropylene with polyethylene. Polymer, 48(10), 29462957. https://doi.org/10.1016/j.polymer.2007.03.037

[3] Owpradit, W. \& Jongsomjit, B. (2008). A comparative study on synthesis of $\mathrm{LLDPE} / \mathrm{TiO}_{2}$ nanocomposites using different $\mathrm{TiO}_{2}$ by in situ polymerization with zirconocene/dMMAO catalyst. Mater Chem Phys, 112(3), 954-961. https://doi.org/10.1016/j.matchemphys.2008.07.050

[4] Chaichana, E., Jongsomjit, B., \& Praserthdam, P. (2007). Effect of nano- $\mathrm{SiO}_{2}$ particle size on the formation of $\mathrm{LLDPE} / \mathrm{SiO}_{2}$ nanocomposite synthesized via the in situ polymerization with metallocene catalyst. Chem Eng Sci, 62(3), 899-905. https://doi.org/10.1016/j.ces.2006.10.005

[5] Zapata, P. A., Palza, H., Cruz, L. S., Lieberwirth, I., Catalina, F., Corrales, T., \& Rabagliati, M. (2013). Polyethylene and poly (ethylene-co-1-octadecene) composites with $\mathrm{TiO}_{2}$ based nanoparticles by metallocenic in situ polymerization. Polymer, 54(11), 2690-2698.

https://doi.org/10.1016/j.polymer.2013.03.048

[6] Palza, H., Reznik, B., Kappes, M., Hennrich, F., Naue, I. F. C., \& Wilhelm, M. (2010). Characterization of melt flow instabilities in polyethylene/carbon nanotube composites. Polymer, 51(16), 3753-3761. https://doi.org/10.1016/j.polymer.2010.06.016

[7] Palza, H., Vergara, R., \& Zapata, P. A. (2011). Composites of polypropylene melt blended with synthesized silica nanoparticles. Compos Sci Technology, 71(4), 535-540. https://doi.org/10.1016/j.compscitech.2011.01.002

[8] Tong, Y., Li, Y., Xie, F., \& Ding, M. (2000). Preparation and characteristics of polyimide- $\mathrm{TiO}_{2}$ nanocomposite film. Polym Int, 49(11), 1543-1547. https://doi.org/10.1002/1097-0126(200011)49:11<1543::AIDPI535>3.0.CO;2-B

[9] Giang, V., Thai, H., Huynh, D., Trung, H., Lam, D. T., \& Tuan, M. V. (2013). Effect of titanium dioxide on the properties of polyethylene $/ \mathrm{TiO}_{2}$ nanocomposites. Compos B-Eng, 45(1), 1192-1198. https://doi.org/10.1016/j.compositesb.2012.09.058

[10] Norio, N. \& Toyoharu, H. (2008). Preparation of $\mathrm{TiO}_{2}$ nanoparticles surface-modified by both carboxylic acid and amine: dispersibility and stabilization in organic solvents. Colloids Surf A, 317, 543-550. https://doi.org/10.1016/j.colsurfa.2007.11.036
[11] Daneshpayeh, S., Ashenai Ghasemi, F., Ghasemi, I., \& Ayaz, M. (2015). Predicting of mechanical properties of PP/LLDPE/TiO2 nanocomposites by response surface methodology. Compos. Part. B, 84, 109-120. https://doi.org/10.1016/j.compositesb.2015.08.075

[12] Garcia, M., Vilet, G. V., \& Jain, S. (2004). Polypropylene/ $\mathrm{SiO}_{2}$ nanocomposites with improved mechanical properties. Rev Adv Mater Science, 6(2), 169-175.

[13] Selvin, T. P. \& Kuruvilla, J. (2004) Mechanical properties of titanium dioxide filled Polystyrene microcomposites. Mater let, 58(3-4), 281-289. https://doi.org/10.1016/S0167-577X(03)00470-1

[14] Wacharawichananat, S., Thongyai, S., \& Tipsri, T. (2009). Effect of mixing conditions and particle sizes of titanium dioxide on mechanical and morphological properties of Polypropylene/Titanium dioxide composites. Iran Polymer journal, 18(8), 607-616.

[15] Altan, N. \& Yildirim, M. (2010). Mechanical and Morgholigical properties of Polypropylene and High density polyethylene matrix composites reinforced with surface modified nano sized $\mathrm{TiO}_{2}$ particles. World Acad Sci Eng Technol, 4(10), 252-257.

[16] Premphet, K. \& Horanont, P. (2000). Phase structure of ternary polypropylene/elastomer/filler composites effect of elastomer polarity. Polym, 41(26), 9283-9290. https://doi.org/10.1016/S0032-3861(00)00303-7

[17] Abughalia, M., Hassan, A., \& Yussuf, A. (2011) Mechanical and Thermal properties of Calcium Carbonate filled PP/LLDPE Composite. J Appl Polym Sci, 121(4), 2413-2421. https://doi.org/10.1002/app.33570

[18] Gang, L., Feng, T. Y., Yuan, Y. F., Cheng, Z. L., Xing, Z. Z., \& Ji, X. Q. (2005). Effect of nanoscale $\mathrm{SiO}_{2}$ and $\mathrm{TiO}_{2}$ as the fillers on the mechanical properties and aging behavior of Linear Low Density Polyethylene/Low Density Polyethylene blends. J Polym Env, 13(4), 339-348. https://doi.org/10.1007/s10924-005-5528-x

[19] Altan, M. \& Yildirim, H. (2012). Mechanical and Antibacterial Properties of Injection Molded Polypropylene/ $\mathrm{TiO}_{2}$ NanoComposites: Effects of Surface Modification. J Mater Sci Technol, 28(8), 686-692. https://doi.org/10.1016/S1005-0302(12)60116-9

[20] Guo, H. \& Li, X. (2012). Preparation and Properties of Transparent SEBS/Titania Nanocomposite Films via Functionalization of SEBS and Sol-Gel Process. Polym Compos, 20(1/2), 155-160. https://doi.org/10.1177/0967391112020001-230

[21] Xue, B., Li, F., Xing, Y., Sun, M., Liu, D., \& Jiang, Y. (2011). Preparation of $\mathrm{Cu} / \mathrm{OMMT/LLDPE}$ nanocomposites and synergistic effect study of two different nano materials in polymer matrix. Polymer Bulletin, 67(8), 1463-1481. https://doi.org/10.1007/s00289-011-0466-3

[22] Montgomery, D. C. (2011). Design and Analysis of Experiments. John Wiley \& Sons, New York.

[23] Box, G. P. G., Hunter, J. S., \& Hunter, W. G., (2005). Statistics for Experimenters: Design, Innovation and Discovery. John Wiley \& Sons, USA. 
Authors' contacts:

\section{Sajjad DANEAHPAYEH}

Faculty of Mechanical Engineering,

Shahid Rajaee Teacher Training University,

Shabanloo St., Lavizan, Tehran, Iran

Tel: +9821-22970060

sajad_danesh66@yahoo.com

\section{Faramarz ASHENAI GHASEMI}

Corresponding author

Faculty of Mechanical Engineering,

Shahid Rajaee Teacher Training University,

Shabanloo St., Lavizan, Tehran, Iran

Tel: +9821-22970060

f.a.ghasemi@sru.ac.ir

faramarz_ashenai_ghasemi@yahoo.com

\section{Ismail GHASEM}

Department of Polymer Processing,

Iran Polymer and Petrochemical Institute (IPPI),

15 km Tehran-Karaj Highway, Pajuhesh Science and Technology Park,

Pajuhesh Boulevard, Tehran 14977-13115, Iran

Tel: +9821-44787050/

I.Ghasemi@ippi.ac.ir 